\title{
«QUE LOS DOS SOMOS UN ALMA / QUE SE PARTIÓ EN DOS MITADES»: EN TORNO A LA AMISTAD EN LA COMEDIA ESPAÑOLA DEL SIGLO DE ORO ${ }^{1}$
}

\author{
«QUE LOS DOS SOMOS UN ALMA / QUE SE PARTIÓ EN DOS MITADES»: \\ ABOUT FRIENDSHIP IN THE SPANISH GOLDEN AGE DRAMA
}

\author{
Esperanza RIVERA SALMERÓN \\ Universidad de Valladolid \\ esperanzamaria.rivera@uva.es
}

\begin{abstract}
Resumen: Nuestros clásicos grecorromanos entendían la amistad como el culmen de toda relación humana y, por ende, como fuente imprescindible de felicidad. Partiendo de ellos, la tradición literaria fue fijando unos tópicos como reflejo de este sagrado vínculo, cuyos hitos principales serán estudiados en este artículo. Destacamos, en este sentido, el papel que representa el teatro barroco, realidad artística que sitúa la amistad como uno de sus motivos principales de conflicto dramático. A modo de ejemplo, analizaremos algunas comedias del dramaturgo barroco Felipe Godínez, quien privilegia este tema dentro de su producción teatral mediante la construcción de estructuras dramáticas que se fundamentan en la tradición y a través de una serie de recursos que serán recurrentes en toda la historia de la literatura.
\end{abstract}

Palabras clave: amistad; felicidad; tradición literaria; teatro barroco; Felipe Godínez.

Abstract: Greek and Roman Classics understood friendship as the culmination of all human relationships and, therefore, as an essential source of happiness. This article will study the main topoi related to this sacred bond coming from the Classics. In this sense, we highlight the role played by baroque theater, an artistic reality that places friendship as one of its main reasons for dramatic conflict. As an example, we will examine some plays by the baroque playwright Felipe Godínez. Within its theater production, this author focuses on this specific topic by forming dramatic structures based on the tradition. He also employs a series of resources that will be recurrent throughout the history of the literature.

Keywords: friendship; hapiness; literary tradition; baroque theater; Felipe Godínez.

\footnotetext{
${ }^{1}$ Este artículo se publica en el marco del Proyecto de Investigación Felicidad y literatura: eficacia social del discurso literario, USAL, Programa IB, 2016, financiado por la Junta de Castilla y León.
} 
El tema de la amistad, con sus diferentes matices y manifestaciones, ha tenido siempre un lugar relevante en la historia de la literatura, tanto en el mundo oriental como en Occidente. Para la cultura de la Antigüedad la amistad es la culminación de todo vínculo personal (Pizzolato 1996) y, por tanto, fuente imprescindible de felicidad.

Si hacemos un breve recorrido por la época clásica, nos encontramos con que grandes pensadores como Sócrates ${ }^{2}$, Platón ${ }^{3}$ y Aristóteles ${ }^{4}$, y grandes literatos romanos, como Plauto, Terencio, Catulo, Cicerón, Virgilio, Horacio, Ovidio, Séneca o $\mathrm{Marcial}^{5}$, tratan en sus obras, y todos ellos concediéndole gran trascendencia, el tema de la amistad (o philía).

Imprescindible es, en este sentido, la Ética a Nicómaco ${ }^{6}$ del Estagirita, en la que este afirma que «el dichoso ['el hombre feliz'] necesita amigos» (Aristóteles 2009: 410) y ofrece una clasificación sobre los tipos de amistad que ha sido capital para el estudio de este motivo en toda la tradición cultural y literaria posterior. Nosotros examinaremos únicamente uno de ellos ${ }^{7}$, la amistad que Aristóteles considera perfecta (basada en el bien), la de los buenos y semejantes en virtud, aquella que, como podemos imaginar, aporta felicidad.

El hito en el mundo romano ${ }^{8}$ lo marca Cicerón y su De amicitia. En él encontramos la consideración del amigo como el alter ego o la otra mitad del yo: «Et alterum anquirit, cuius animum ita cum suo misceat, ut efficiat paene unum ex duobus» (Cicerón 2002, XXI, 98), es decir, ‘Éste no solo se ama a sí mismo, sino que busca afanosamente a otro con cuya alma mezclar la suya, de suerte que, de las dos, se forme casi una sola' ${ }^{9}$. Del mismo modo, hemos de recordar las palabras que Horacio

\footnotetext{
${ }^{2}$ Es el primero en intentar explicar el amor entre amigos, definiéndolo como la voluntad de «desear que la persona amada sea lo más feliz posible» (Merino 2006: 63).

${ }^{3}$ Quien diferencia entre las relaciones amistosas (philía) y amorosas (eros). Véase, en este sentido, Pizzolato 1996: 66-79, Villapalos 2000: 24-32 y Vallejo 2009.

${ }^{4}$ Sobre estos tres pensadores y su relación con la amistad, Laín Entralgo 1986: 31-55; sobre la concepción aristotélica de este tema, Calvo Martínez 2000. Para profundizar de una forma más amplia en el mundo griego en general, Pizzolato 1996: 15-138, Villapalos 2000: 13-41 y Merino 2006: 58-70.

${ }^{5}$ Sobre el tema de la amistad en Roma véanse, por ejemplo, Pizzolato 1996: 139-314, Villapalos 2000: 43-68 y Merino 2006: 109-138.

${ }^{6}$ Los libros VIII y IX están dedicados precisamente al estudio de la amistad. Véanse en la traducción de Rus y Meabe: Aristóteles 2009: 325-419.

${ }^{7}$ Los otras dos son la amistad por utilidad y la amistad por placer; ambas suponen interés y por ello son consideradas amistades imperfectas.

${ }^{8}$ Donde el tema de la amistad pasa a formar parte también del discurso político.

${ }^{9}$ Traducción de José Guillén Caballero. Idea que Cicerón comienza a desarrollar de manera más extensa unas líneas antes (XXI, 97): «Ipse enim se quisque diligit, non ut aliquam a se ipse mercedem exigat caritatis suae, sed quod per se sibi quisque carus est. Quod nisi idem in amicitiam transferetur, verus amicus numquam reperietur; est enim is qui est tamquam alter idem»: 'Pues todo el mundo se ama a sí mismo no para sacar de sí algún provecho de su amor, sino porque cada uno se ama a sí mismo por su propia naturaleza. Y si esto no se traslada tal cual a la amistad, jamás se encontrará un amigo verdadero, que lo es, en efecto, el que es «como un segundo uno mismo»'.
} 
dedica a Virgilio en la oda I, 3: «Serves animae dimidum meae» ('Y que mantengas a salvo a la mitad de mi alma' ${ }^{10}$ o unas semejantes de Ovidio en los Tristia (elegía IV, 4): «Qui duo corporibus mentibus unus erant»: 'Que eran dos en cuerpo y uno en alma' (haciendo referencia, en este caso, a la tópica pareja de amigos que forman Orestes y Pílades). Esta idea será muy recurrente en la literatura posterior, como veremos más adelante en algunos fragmentos pertenecientes a varias comedias barrocas.

Esencial es la amistad también, como sabemos, en la concepción que el epicureísmo tiene de la vida. Lejos de creer que la persona puede ser feliz en soledad, Epicuro y su escuela defienden la búsqueda de la paz y de la felicidad siempre en compañía de buenos amigos ${ }^{11}$. Destaca, en este sentido, el famoso epigrama de Marcial $(X, 47)$ en el que la amistad se sitúa como uno de los indispensables ingredientes que el hombre ha de adquirir para ser feliz plenamente: el poeta aconseja a su amigo Julio Marcial tener «pares amici».

Además de todas estas ideas que hemos rescatado del pensamiento de los clásicos, los textos literarios se nutren de otro recurso fundamental en su ensalzamiento de la amistad: la referencia a las grandes parejas de amigos que forman muchos de los héroes del mundo grecorromano. Estos son Teseo y Pirítoo, Aquiles y Patroclo, los citados Orestes y Pílades, Niso y Euríalo, Eneas y Acates o Hefestión y Alejandro ${ }^{12}$, muchos de los cuales aparecerán de forma recurrente en los versos de las comedias barrocas.

La tradición cristiana ${ }^{13}$ también es partícipe de este motivo tan universal y, como hace con prácticamente todos los temas paganos, va a «cristianizar» el concepto de amistad que recibe de los antiguos. Ese «amar al amigo como a uno mismo» que comentábamos hace un momento pasará a ser el mandamiento de los mandamientos entre los cristianos: «Amarás a tu prójimo como a ti mismo» (Lev. 19, 18). E, igualmente, este valor será protagonista en los Evangelios, donde Cristo se dirige a sus discípulos como un amigo:

Nadie tiene amor mayor que éste de dar uno la vida por sus amigos. Vosotros sois mis amigos si hacéis lo que os mando. Ya no os llamo siervos, porque el siervo no sabe lo que hace su señor; pero os digo amigos, porque todo lo que oí de mi Padre os lo he dado a conocer. Esto os mando, que os améis unos a otros (Juan $15,13-15,17)$.

${ }^{10}$ Esas palabras están dirigidas, en realidad, al barco que llevará a su amigo mantuano a Grecia. Es, pues, un poema propempticon ('de deseo de buen viaje').

11 «De todos los bienes que la sabiduría procura para la felicidad de una vida completa, el mayor con mucho es la adquisición de la amistad» (Máximas Capitales, XXVII, en Epicuro 2009: 96) o «La amistad recorre el mundo entero proclamando a todos nosotros que despertemos ya a la felicidad» (Sentencias Vaticanas, 52, en Epicuro 2009: 103).

${ }^{12}$ Amigos por antonomasia son también los filósofos pitagóricos Damón y Pintias (o Fintias). Es significativo, en este mismo sentido, el listado que el humanista del siglo XVI Ravisio Téxtor aportaba en su célebre Officina sobre amigos queridísimos (título VII, capítulo «Amici arctissimi»), lo que quiere decir que, efectivamente, se utilizaban mucho para ejemplificar.

${ }^{13}$ No nos detenemos en la consideración que sobre la amistad ofrecen algunos de los grandes pensadores de la Iglesia, como San Pablo, San Ambrosio, San Agustín, Santo Tomás o San Bernardo (entre otros), así como el cisterciense inglés Aelred Rievaulx (en su De spiritale amicitia), pero hemos de reseñar que también ellos le dedican un considerable espacio en varias de sus obras. Para todo ello véase, por ejemplo, Serés 1996: 44-53, Pizzolato 1996: 393-465 y Villapalos 2000: $87-131$. 
Además, en Mateo 22, 39 se repetirá la citada sentencia del Levítico. En esta misma línea y como sucedía con la recurrencia a los héroes clásicos, también la literatura va a beber de los modelos que encontramos en los textos cristianos, fundamentalmente en el Antiguo Testamento; entre ellos destaca la pareja formada por David y Jonatán.

La tradición posterior que continúa desarrollándose desde la época medieval hasta el barroco mantiene ese amor por el tema de la amistad y, así, percibimos su presencia en algunas de las obras más relevantes de este período. Es interesante citar la importancia que tuvo el famoso cuento de los dos amigos, de origen oriental, que desde el siglo XII se difundió en Europa y, particularmente, en España (a partir de la Disciplina clericalis de Pedro Alfonso), apareciendo en varias obras difundidas desde ese momento hasta al menos el siglo XVII, entre las que podemos destacar El libro del caballero Cifar, El Patrañuelo de Timoneda o El curial del Parnaso de Matías de los Reyes (sobre su tradición literaria, véase Avalle-Arce 1957). Por otro lado, uno de los libros más relevantes del siglo XVI es, sin duda, el Cortesano de Baltasar Castiglione y en él también encontramos, en esa conformación del cortesano perfecto como ideal de perfección humana, unas reflexiones en el libro II dedicadas a la importancia de cultivar la amistad; se cita además a algunas de las famosas parejas de amigos clásicos a las que hacíamos referencia anteriormente. El Quijote, por su parte, es también un claro ejemplo de la vigencia del tema en los siglos de Oro, ya no solo por la relación de amistad que se da entre don Quijote y Sancho, sino también por los diferentes relatos intercalados que presentan dicho asunto como tema sustancial, como es el del Curioso impertinente o algunos de los famosos sonetos de Cardenio y Lotario, estudiados por Mata 2005.

\section{La amistad en el teatro barroco: el caso de Felipe Godínez}

Todo el acervo que se va conformando a lo largo de los siglos en torno a este motivo es retomado por los dramaturgos del Siglo de Oro, quienes adaptan y reflejan esa idea de amistad en muchos de sus versos, convirtiéndolo en uno de los temas más reiterados en la comedia nueva.

Podemos sostener esta afirmación simplemente asomándonos a muchos de los títulos de estas comedias: El amigo hasta la muerte, El amigo por fuerza, La amistad pagada, La prueba de los amigos (Lope de Vega), El amor y la amistad, Cómo han de ser los amigos (Tirso de Molina), Amor, lealtad y amistad (Montalbán), Amigo, amante y leal (Calderón), No hay amigo para amigo, Sin honra no hay amistad (Rojas Zorrilla), La amistad castigada, Ganar amigos (Ruíz de Alarcón), El mejor amigo, el rey, El poder de la amistad, El secreto entre dos amigos (Moreto), La traición en la amistad (Zayas y Sotomayor), Cautelas son amistades (Godínez), etc. ${ }^{14}$. Pero, además, será también tema principal o secundario de otras muchas que no lo anuncian en sus títulos ${ }^{15}$, suponiendo de igual forma uno de los

\footnotetext{
${ }^{14}$ En el Catálogo de Urzáiz (2002) encontramos un total de 78 comedias con esta peculiaridad.

${ }^{15}$ Algunos de ellos son La boda entre dos maridos, La pastoral de Jacinto, Los torneos de Aragón, El hijo de Reduán, Los palacios de Galiana... de Lope de Vega; Mujer, llora y vencerás, Basta callar, Saber del mal y del bien, El galán fantasma, Nadie fíe su secreto, El segundo Escipión, La dama duende... de Calderón de la Barca. Para el estudio de este tema y un elenco más amplio de títulos de comedias que tratan este asunto, véase González-Barrera 2008 en el caso de Lope de Vega, Bentley 1996, Zugasti 2001 (quien, además, presenta un estudio introductorio de la historia de este motivo desde sus
} 
motores esenciales del desarrollo dramático de la acción, que se construye generalmente en torno a un triángulo amoroso y prácticamente siempre mediante las relaciones de dos parejas de galanes y damas. Aparecerá, pues, íntimamente ligado a los temas del amor, los celos y el honor.

Cabe señalar, igualmente, que dicho motivo tiene presencia en todo tipo de géneros, es decir, tanto en las comedias serias como en las cómicas, además de en el auto sacramental. Lo cierto es que el subgénero que se convierte en el cauce más idóneo para la expresión de la amistad es la llamada comedia palatina seria ${ }^{16}$, denominación que, en pocas palabras, engloba a aquellas comedias de enredo que se enmarcan en un ambiente extranjero, en palacio, protagonizadas por personajes de altas clases sociales y en cuya acción sucede algún hecho trágico o de tono grave (elemento este último que las distancia de las comedias palatinas por antonomasia, las cómicas). Zugasti (2001: 158) habla incluso de un subtipo al que etiqueta como «comedia de amistad» y en que el motivo que estamos estudiando alcanza una total relevancia, por encima, pues, de los grandes temas del teatro áureo.

Por otro lado, los diferentes esquemas de relaciones amistosas que encontraremos en estas comedias son los mismos que la tradición ha consagrado y que podemos encontrar clasificados en el índice de motivos folclóricos de Thompson (1966). Habrá variantes en cuanto al desarrollo de las tramas de una u otra acción, pero podemos confirmar una homogeneidad en el tratamiento del motivo central. Así, destacan los casos en que un hombre se ofrece a morir por otro, el hombre que conoce un plan por el que matarán a un amigo y se disfraza y muere en su lugar, la negativa a creer que un amigo ha hablado mal de él, el hombre que cede la dama al amigo, pruebas de amistad varias para descubrir al auténtico amigo, etc. Pero todas ellas se pueden reducir, a nuestro modo de ver, a dos grupos fundamentales: la anteposición de la amistad al amor hacia una mujer y la capacidad de defender e incluso dar la vida por el amigo, como veremos en algún ejemplo a continuación.

Es indiscutible que los grandes dramaturgos del Siglo de Oro español son Lope de Vega y Calderón de la Barca, seguidos en importancia por Tirso de Molina. Pero como ocurre con todas las realidades literarias de la época, también hubo un gran número de escritores de «segunda fila», que entonces no lo eran tanto, cuyas piezas teatrales tuvieron igualmente éxito y presencia en las carteleras de la época. Dentro de esta nómina de autores encontramos a Felipe Godínez (1582-1659), onubense nacido en Moguer que vivió a caballo entre los dos grandes creadores del teatro barroco.

Precisamente por ser considerado un autor «de los márgenes», que diríamos hoy en día, durante mucho tiempo sufrió un abandono absoluto por parte de la crítica. Con algún trabajo testimonial a finales del siglo XIX, no será hasta la década de los setenta del siglo XX cuando la figura y obra de Felipe Godínez comiencen a ser objeto de un estudio amplio y serio. A la publicación de una serie de trabajos dedicados tanto a su biografía (muy interesante por su condición de converso y por su comparecencia en un auto de fe en 1624 acusado de «hereje» y «judaizante») como a su producción

orígenes grecolatinos hasta el siglo XVII esclarecedor y riguroso) y Gil-Osle 2015 para Calderón. Sobre la amistad en las dos comedias palatinas citadas de Tirso de Molina, puede verse la edición de Otal 2007. Y, por último, en torno a la amistad en los personajes femeninos (también tratados por Gil-Osle en su estudio) de La traición en la amistad de María de Zayas, Santolaria 1998.

${ }^{16}$ Para esta terminología, véanse los trabajos de Zugasti, en particular el más reciente de 2015. 
dramática (formada por veintiuna comedias de autoría segura, quince religiosas y seis profanas), le han seguido otros que continúan hasta nuestros días ${ }^{17}$.

Uno de los temas «estrella» de la producción godinesca es precisamente la amistad, pues recorre muchos de los versos de sus comedias, así como sirve de recurso estructural de varias de las acciones que en ellas se suceden. Destacan, en este sentido, las relaciones de amistad desarrolladas en algunas de sus comedias religiosas más aplaudidas como son Las lágrimas de David (entre Urías y Joab) o Los trabajos de Job (entre Baldad, Elifaz, Sofar y Job). Nosotros analizaremos, en cambio, tres de sus comedias cortesanas (de asunto profano), consideradas «serias de enredo palatino» (Vega 2004: 111) y escritas todas ellas en la década de esplendor del teatro barroco: Aun de noche alumbra el sol (163033), Cautelas son amistades (1630-34) y Basta intentarlo (1635-37) ${ }^{18}$.

Por un lado, veremos cuáles son los esquemas dramáticos con que se construyen estas comedias y, siguiendo la clasificación de Thompson, cuáles son las opciones estructurales en que se desarrolla el tema de la amistad. Por otro lado y de manera complementaria, nos detendremos en la forma de expresión de este motivo, en los diferentes recursos tradicionales que utiliza Godínez para manifestar ese sentimiento sublime de amistad que existe entre sus personajes.

En Aun de noche alumbra el sol ${ }^{19}$, la trama principal se sostiene a través de dos temas fundamentales: el amor y el honor, pero, como veremos, la amistad posee también una relevancia sustancial en el devenir de la acción. Don Juan de Estúñiga se ha casado en secreto con doña Sol, mujer que, a su vez, es pretendida por el príncipe don Carlos. Este (que no sabe que están casados) se entera de que el galán sigue cortejándola y, para evitarlo, pide a don Jaime, el tercer galán de la comedia, que le dé muerte. Este se niega apelando al vínculo sagrado que los une, la amistad, y pide a su amigo que se aleje por un tiempo del reino. Encontramos, pues, en estas primeras escenas la desobediencia de un galán a su rey en aras de la defensa de la vida de un amigo. Posteriormente, otra de las damas de la comedia, doña Costanza, que está también enamorada de don Juan, urde un enredo para perjudicar a doña Sol. Decide hacerse pasar por la pretendida dama, aprovechando la oscuridad de la noche, para atender los requiebros del príncipe Carlos, con tan mala suerte de que en una de sus conversaciones son escuchados por don Jaime, responsable de cuidar el honor de su amigo y decidido a limpiar esa deshonra. Se desarrolla, por tanto, en esta segunda variante esa íntima relación entre la amistad y el honor, lealtad que don Jaime expresa con unas bellas palabras que convierten el deshonor ajeno en la pérdida del propio honor, ya que considera como suyo lo que le sucede a su amigo («que eran dos en cuerpo y uno en alma», como decía Ovidio en sus Tristia):

JAIME. (Aparte.)

Sin que me sientan he entrado

(todo la industria lo pudo)

\footnotetext{
${ }^{17}$ Véase el estado de la cuestión llevado a cabo por Menéndez Onrubia 2009. Además, hemos de añadir estudios posteriores y determinantes como los de Vega 2009a, 2009b, y los de Sánchez-Cid, entre los que destacamos el más reciente de 2016. ${ }^{18}$ Las dos últimas pueden considerarse, por los elementos que las constituyen, palatinas serias. Apoyamos, pues, la teoría de Zugasti, que estima este subgénero como el más proclive a desarrollar el tema de la amistad.

${ }^{19}$ Es esta una de las pocas comedias del onubense que cuenta con una edición moderna. Véase, si se quiere profundizar en ella, la introducción de Bolaños y Piñero 1991: 31-49.
} 


\author{
mientras el silencio mudo \\ recatos presta al cuidado; \\ que, guardando ajeno honor, \\ si es ajeno el de mi amigo, \\ las sombras del miedo sigo \\ con los pasos del temor \\ adonde el ardid se atreve, \\ fiado a noche tan ciega, \\ que el sol hay noches que niega \\ la luz que a los astros debe (vv. 934-945).
}

Cautelas son amistades ${ }^{20}$ presenta también una pareja de amigos, ambos llamados Carlos, con el matiz particular de que son dos supuestos hermanos. En realidad, uno de ellos (llamado, por cierto, Conde en la comedia para diferenciarlo del otro Carlos) es el secreto hijo del Rey y heredero legítimo de la corona. Estos dos personajes son dos soldados que han luchado en Milán y llegan a Nápoles con el deseo de que el monarca les reconozca sus méritos. Allí se encuentra don Enrique, sobrino del Rey y hasta ese momento el sucesor al trono; cuando este se entera de que uno de los dos Carlos (no sabe todavía quién de los dos) puede quitarle su lugar, planea matarlo. Con lo que no cuenta Enrique es con que su intención es también escuchada por César, padre de Carlos y único personaje que sabe toda la verdad. Este desvela a su hijo quién es el Conde en realidad, lo que le lleva a hacerse pasar por él para salvaguardar su vida, aunque lleve consigo poner en peligro la suya propia:

CARLOS.
Pues, padre, Carlos me deba
la más generosa acción,
la más heroica fineza:
extrañarás por ventura
determinación tan nueva,
mas hasta haberme escuchado
no repliques ni obedezcas.
No he de fiar, vive Dios,
su vida a la contingencia,
sino, arriesgando la mía,
comprar la suya con ella.
Carlos somos ambos: $\mathrm{di}$,
cuando a preguntarlo vengan,
que el hijo del Rey soy yo (vv. 1538-1551).

A Nápoles también ha llegado la Duquesa, mujer guerrera a quien le han quitado su título en la guerra. Los dos soldados están enamorados de ella, pero la dama solo corresponde a uno de ellos, a Carlos, quien será capaz de renunciar a su amor por la amistad que le une a su «hermano» el Conde. Un ejemplo de ello son las siguientes palabras que el galán declama en un aparte de la comedia:

CARLOS.

¿Qué es esto?
En muchos riesgos me he puesto.
Son por Carlos: pocos son.
Él, en fin, es el Infante
de Nápoles y aun el Rey:

\footnotetext{
${ }^{20}$ Actualmente estamos trabajando en la edición de esta comedia, por lo que la numeración de los versos y la puntuación de los mismos son nuestros.
} 
Vemos, pues, que tanto en la trama política como en la amorosa la amistad es el motor esencial de la acción, convirtiéndose en uno de los temas fundamentales de la pieza. De igual forma, podemos clasificar estas dos principales estructuras dramáticas basándonos en aquellas que señalábamos a partir del análisis de Thompson: la capacidad de dar la vida por un amigo y la amistad como el valor más importante de todos, situado incluso por encima del amor.

Basta intentarlo ${ }^{21}$, por su parte, presenta el tema de la amistad de una manera aparentemente secundaria, pero veremos que es esencial en el desenlace de la trama. Don Juan, secretario del monarca, está casado con doña Blanca, una hermosa y atractiva dama que es también admirada por otro de los galanes de la comedia, Tello, quien en cambio antepone la amistad que le une a don Juan al deseo amoroso que siente por ella. Por otro lado, se desarrolla una intriga semejante a la que encontrábamos en Aun de noche alumbra el sol, en la que el honor y la amistad transcurren nuevamente de la mano: un tercer galán aparece en acción con el fin de pretender a doña Blanca y, en ese deseo de cortejarla, le envía un billete que es interceptado por el Rey. Este, amigo también de su secretario don Juan, no cejará en la búsqueda del traidor para darle muerte. Se repiten, por tanto, las estructuras principales que presentamos en su momento: la amistad como sentimiento situado por encima del amor y la defensa de la vida del amigo, en este caso a través de la limpieza del honor mancillado.

Hemos mostrado, pues, cómo estas tres comedias se construyen a partir de unas estructuras semejantes (herederas, además, de la tradición) en que la amistad tiene una vital importancia. Veamos ahora brevemente cómo se expresa ese enaltecido valor: con qué lenguaje y con qué recursos presenta Godínez, a través de sus personajes, la importancia de la amistad. En primer lugar, traemos a colación dos fragmentos que recuerdan la idea clásica y tradicional que considera al amigo como la otra mitad del yo (acordémonos de las citas de Cicerón, Horacio y Ovidio al respecto):

CONDE.

\author{
Somos muy uno, y si digo \\ que fui más, y menos fui, \\ seremos dos, y no hay causa \\ que nos pueda dividir (vv. 433-436).
}

Este primer fragmento pertenece a Cautelas son amistades y muestra esa íntima y recíproca idea de amistad fraternal que existe entre el Conde y Carlos. En el siguiente, de Basta intentarlo, encontramos otra importante pareja de amigos, la formada por Tello y don Juan (asimismo, se deduce la amistad que les une al Rey). El galán protagonista resume, a través de dos versos muy bellos (que dan título, por cierto, a este trabajo), esa imagen de unión absolutamente inseparable que se da entre ellos, la unión del alma:

\footnotetext{
${ }^{21}$ Nos consta que se está trabajando en su edición moderna, pero hasta el momento se encuentra inédita. Citamos, pues, por uno de sus testimonios impresos; en concreto, el T/55344-18 de la Biblioteca Nacional.
} 
TELLO.

\author{
Mucho siento, \\ don Juan, dos enfermedades \\ a fe de hidalgo: la vuestra \\ DON JUAN. \\ y la del Rey.
}

Dios os guarde que se partió en dos mitades (fol. 3v).

Este estrecho vínculo se desarrolla también a través de una de las metáforas más tópicas de la historia de la literatura en Aun de noche alumbra el sol y en Cautelas son amistades, la alegoría clásica y tradicional del olmo y la vid ${ }^{22}$. En el primer caso, expresa la indisoluble unidad que forman los enamorados:

SOL.

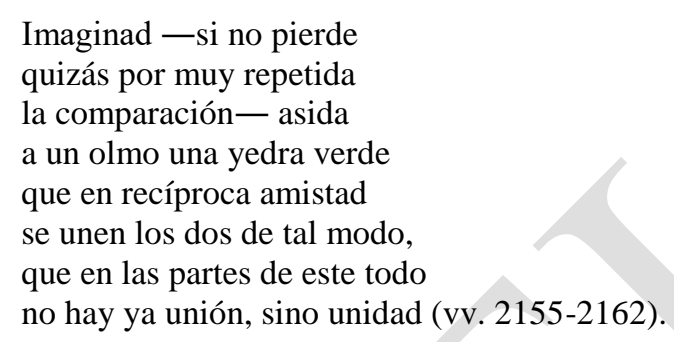

Y, en el segundo, esa armonía en la relación paterno-filial existente entre Carlos y el Rey:

CARLOS.

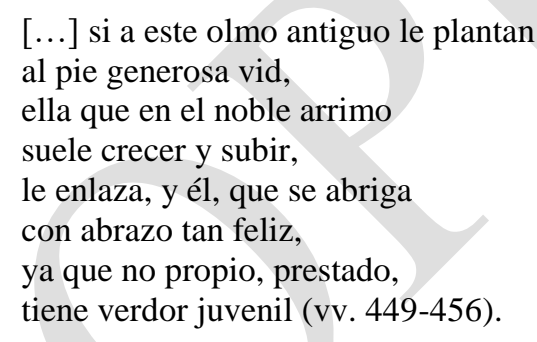

Pero ambos, de ahí que traigamos esta bella imagen a nuestro análisis, remiten (Aun de noche alumbra el sol, además, de forma literal) a la íntima relación de amistad que presenta Andrea Alciato a través de esta metáfora en su emblema CLX, que reza «La amistad que dura aun después de la muerte» (Amicitia etiam post mortem durans) y en la que la pictura ofrece un olmo viejo al que la vid se anuda rodeándolo ${ }^{23}$. Se toma, pues, una de las imágenes antonomásticas de la amistad para referirse a otros tipos de amor, pero queda sin duda la reminiscencia al amor más puro de todos, que es, según nuestros clásicos, el que dos amigos, cual olmo y vid, alimentan y sostienen recíprocamente.

Apuntábamos también que una de las formas más comunes de enaltecimiento de este valor entre dos personas puede expresarse con referencias a algunas de las parejas de amigos más célebres del

\footnotetext{
${ }^{22}$ Que tiene sus precedentes grecorromanos en Virgilio, Catulo y la Antología griega, fundamentalmente.

${ }^{23} \mathrm{El}$ pie suscribe: «Al olmo viejo, seco y sin verdura, / la parra fresca y verde entretexida / es encubierto exemplo en tal figura / que al' amistad durable nos conbida. / Pues no es perfecto amor el que no dura / al menos hasta el ir de aquesta vida. / Bueno será buscar amigos tales / que quedos siempre estén a nuestros males» (versión de Daza Pinciano 1549: 31).
} 
mundo grecorromano. Esto mismo sucede en Godínez, como podemos ver en estos dos ejemplos de Basta intentarlo:

TELLO.

Somos los dos tan amigos, que hipérboles y memorias de los Pílades y Orestes con nuestra amistad se borran (fol. 1).

CONDE.
En fin, Eneas y Acates, Efestión y Alejandro, no fueron amigos tales como Tello de Mendoza y don Juan Osorio; aun antes de oír lo que después supe, vi que eran muy desiguales para amistad tan estrecha los gustos y las edades (fol. 4).

Pílades y Orestes, Eneas y Acates, Hefestión y Alejandro... Algunos de los grandes amigos de la historia de nuestros clásicos no tienen nada que envidiar a la relación de amistad que existe entre Tello y don Juan, quienes los sobrepujan en ese aspecto. Recordemos que el primero sitúa ese nexo de unión con su amigo por encima del deseo amoroso y, se entiende, por encima de todo lo demás.

El héroe troyano y su inseparable amigo son también nombrados en Cautelas son amistades, en este caso en boca de Gandalín, el gracioso de la comedia:

GANDALÍN.

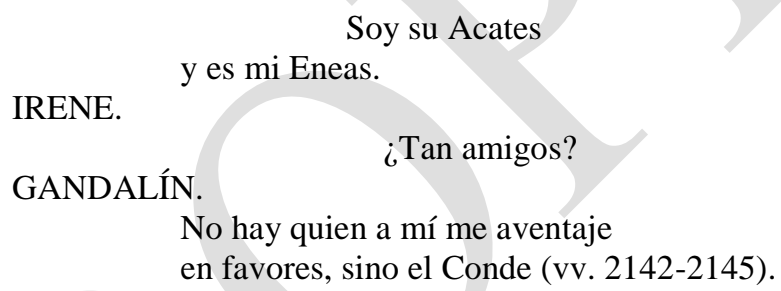

Acates es el compañero fidus de su señor, Eneas, y así se siente también Gandalín con su amo el Conde. Esa lealtad es para él una manera de amistad y recurre a una de las parejas más tópicas y la que mejor puede expresar esa relación para indicar su eterna fidelidad. Imposible no acordarnos, en este caso, de otra de las parejas más famosas de la literatura universal, como es la formada por Don Quijote y Sancho, caballero y escudero que se configuran como paradigma de la amistad.

\section{Unas breves conclusiones}

Como vemos, pues, el teatro barroco, incluso en aquellos dramaturgos hoy considerados menores, recoge la tradición literaria del tema que estamos estudiando para otorgarle un lugar primordial en muchos de sus versos. Se convierte, así, en un elemento sustancial para el desarrollo dramático, ya que, después de las relaciones amorosas que existen entre los diferentes personajes que 
salen a escena, las amistosas son las que mejor funcionan en las tablas, pues proporcionan enredo, intriga, dinamismo y atracción en el espectador.

Amigos queridísimos son ciertamente Acates y Eneas o Hefestión y Alejandro, pero a ese listado clásico se han ido uniendo otras parejas de amigos, reales o de ficción, muchas de ellas así consagradas por la literatura, como Garcilaso y Boscán, Michel de Montaigne y Étienne de La Boétie, los citados Don Quijote y Sancho, Lotario y Anselmo, Sherlock Holmes y su inseparable Watson, Goethe y Schiller, Miguel Hernández y Ramón Sijé, García Lorca y Sánchez Mejías, o, en nuestra actualidad más o menos reciente, a través del cine, del cómic o de la animación, Oliver y Benji, Zipi y Zape, Asterix y Obelix, Timón y Pumba, Bob Esponja y Patricio, Mortadelo y Filemón, Woody y Buzzlightyear (recordemos su «hay un amigo en mí»), etc., etc. El teatro barroco se sitúa, pues, como un eslabón más dentro de esta tradición literaria y hace, así, protagonistas de sus versos a muchas otras parejas que, aunque no hayan pasado como tal a la posteridad, nutren igualmente su relación de amistad.

En suma, y de acuerdo con las palabras del reconocido filósofo alemán Wilhelm Schmid (2016: 14), «cultivar la amistad se convierte, en todo caso, en un elemento del arte de la vida siempre que el individuo sea consciente de lo imprescindible de esta relación para que la vida sea bella» y para que, de esta suerte, el hombre pueda alcanzar esa felicidad que anhela en cada uno de sus días.

\section{Bibliografía}

ARISTÓteles (2009): Ética a Nicómaco. Trad. S. Rus Rufino y Joaquín E. Meabe. Madrid, Tecnos. AvAlLE-ARCE, Juan Bautista (1957): «Una tradición literaria: el cuento de los dos amigos», Nueva Revista de Filología Hispánica, 11/1, pp. 1-35.

BENTLEY, Bernard P. E. (1998): «Apuntes para la caracterización de los galanes en el Antes que todo es mi dama de Calderón», en María Cruz GARCíA DE EnTERría y Alicia Cordón MeSA, eds., Actas del IV Congreso Internacional de la Asociación Internacional Siglo de Oro (AISO), Alcalá de Henares, 22-27 de julio de 1996. Alcalá de Henares, Universidad de Alcalá, vol. I, pp. 225235.

Bolaños Donoso, Piedad - Piñero Ramírez, Pedro M., eds. (1991): Felipe Godínez, Aun de noche alumbra el sol. Los trabajos de Job. Kassel / Sevilla, Reichenberger / Universidad de Sevilla.

CAlvo Martínez, Tomás Mariano (2003): «La concepción aristotélica de la amistad», Bitarte. Revista cuatrimestral de humanidades, 30, pp. 29-40.

Cicerón, Marco Tulio (2002): De amicitia. Trad. José Guillén Cabañero. Madrid, Trotta.

DAZA PINCIANO, Bernardino (1549): Los emblemas de Alciato traducidos en rhimas españolas. Lyon, Mathia Bonhome.

GIL-OsLe, Juan Pablo (2015): «El debate de la amicitia de las damas en Calderón de la Barca», en Frederick A. DE ARMAS y Antonio SÁNCHEZ JimÉnEZ, eds., Nuevas sonoras aves. Catorce 
estudios sobre Calderón de la Barca. Madrid / Frankfurt am Main, Iberoamericana / Vervuert, pp. 215-226.

GodínEz, Felipe (1630-34): Cautelas son amistades. Comedia famosa del doctor Felipe Godínez. T/55324/11, Madrid, Biblioteca Nacional de España.

(1635-37): Basta intentarlo. Comedia famosa del doctor Felipe Godinez, T/55344/18, Madrid, Biblioteca Nacional de España.

GONZÁLEZ-BARRERA, Julián (2008): «El valor de la amistad para Lope de Vega: una huella viva de la Antigüedad grecolatina», Cuadernos de Filología Clásica. Estudios latinos, 28/1, pp. 139-150.

LAín EnTRAlgo, Pedro (1986): Sobre la amistad. Madrid, Espasa-Calpe.

MATA InDURÁIN, Carlos (2005): «Del amor y la amistad en la primera parte del Quijote: los sonetos de Cardenio y Lotario», en Chul PARK, coord., Actas del XI Coloquio Internacional de la Asociación de Cervantistas, Seúl, 17-20 de noviembre de 2004. Seúl, Universidad de Hankuk, pp. 147-162.

MERINO, Ignacio (2006): Elogio de la amistad. Una historia de la amistad desde la Antigüedad hasta nuestros días. Barcelona, Plaza \& Janés.

Pizzolato, Luigi (1996): La idea de la amistad. Trad. José Ramón Monreal. Barcelona, Muchnik.

SÁNCHEZ-CID, Francisco Javier (2016): La familia del dramaturgo Felipe Godínez. Un clan judeoconverso en la época de la Contrarreforma. Huelva, Universidad de Huelva.

SANTOLARIA SOlANO, Cristina (1998): «Teatro y mujer en el siglo de Oro: La traición en la amistad de Da María de Zayas y Sotomayor», en María Cruz GARCíA DE EnTERRÍA y Alicia Cordón MESA, eds., Actas del IV Congreso Internacional de la Asociación Internacional Siglo de Oro (AISO), Alcalá de Henares, 22-27 de julio de 1996. Alcalá de Henares, Universidad de Alcalá, vol. II, pp. 1479-1490.

SERÉS, Guillermo (1996): La transformación de los amantes. Imágenes del amor de la Antigüedad al Siglo de Oro. Barcelona, Crítica.

SCHMID, Wilhelm (2016): De la fortuna de la amistad. Trad. Ela Fernández-Palacios. Valencia, PreTextos.

Otal, María Teresa, ed. (2007): Tirso de Molina, Cómo han de ser los amigos y El amor y el amistad (dos comedias palatinas). Madrid / Pamplona, Revista Estudios / GRISO (Universidad de Navarra).

Thompson, Stith (1966): Motif-Index of Folk-Literature: A Classification of Narrative Elements in Folktales, Ballads, Myths, Books, and Local Legends. Bloomington-London, Indiana University Press.

URZÁIZ ToRTAJADA, Héctor (2002): Catálogo de autores teatrales del siglo XVII. Madrid, Fundación Universitaria Española.

VAllejo CAmpos, Álvaro (2009): «Èros y philía en Platón y Aristóteles», en José María ZamoRA CAlvo, ed., La amistad en la filosofía antigua. Madrid, Universidad Autónoma de Madrid, pp. 63-78. 
60 Tropelías. Revista de Teoría de la Literatura y Literatura Comparada, 30 (2018)

Esperanza Rivera Salmerón

VARA, José, ed. (1996): Epicuro, Obras completas. Madrid, Cátedra.

VEga GARCÍA-LUENGOS, Germán (2009a), «Un balance de la recuperación del legado vital y literario de Felipe Godínez», en Felipe GodínEZ, Finis Vitae. Testamento y codicilo de Felipe Godínez (1-2 de diciembre de 1659). Moguer, Sociedad Estatal de Conmemoraciones Culturales, pp. 1333.

(2009b): «Sobre la singularidad vital y dramática de Felipe Godínez», Montemayor. Monográfico especial. 350 aniversario de la muerte del poeta y dramaturgo Felipe Godínez. Moguer, Fundación Municipal de Cultura de Moguer, pp. 17-25.

Villapalos, Gustavo (2000): El libro de la amistad. Barcelona, Martínez Roca.

ZugastiZugASTI, Miguel (2001): «Presencia de un motivo clásico en Calderón: el galán que renuncia al amor de su dama en favor de un amigo o vasallo», en Felipe B. PEDRAZA JiMÉNEZ, Rafael GonZÁlez CAÑAl y Elena E. MARCELlo, eds., Calderón, sistema dramático y técnicas escénicas: actas de las XXIII Jornadas de teatro clásico, Almagro, 11, 12 y 13 de julio de 2000. Ciudad Real, Universidad de Castilla-La Mancha, pp. 155-186.

(2015): «Deslinde de un género dramático mayor: comedia palatina cómica y comedia palatina seria en el Siglo de Oro», en Miguel Zugasti y Mar ZubiETA, eds., La comedia palatina del Siglo de Oro. Cuadernos de Teatro Clásico, 31, pp. 65-102. 